\title{
Effects of Unloading Rate on Energy Evolution Mechanism in the Single-Side Unloading Failure of Highly Stressed Marble
}

\author{
Wensong Xu $\left(\mathbb{D},{ }^{1,2}\right.$ Guangming Zhao ${ }^{1},{ }^{1,2}$ Xiangrui Meng, ${ }^{1,2}$ Siming Kao, ${ }^{1,2}$ \\ Shunjie Huang, ${ }^{1,2}$ and Chongyan Liu ${ }^{1,2}$ \\ ${ }^{1}$ MOE Key Laboratory of Coal Mine Safety and High Efficiency Mining, Anhui University of Science and Technology, Huainan, \\ Anhui 232001, China \\ ${ }^{2}$ School of Mining and Safety Engineering, Anhui University of Science and Technology, Huainan, Anhui 232001, China
}

Correspondence should be addressed to Wensong Xu; 359879021@qq.com and Guangming Zhao; guangmingzhao@163.com

Received 23 September 2019; Revised 1 January 2020; Accepted 18 January 2020; Published 9 April 2020

Academic Editor: Wayne Yu Wang

Copyright ( 92020 Wensong Xu et al. This is an open access article distributed under the Creative Commons Attribution License, which permits unrestricted use, distribution, and reproduction in any medium, provided the original work is properly cited.

Highly stressed rock masses continuously exchange substances and energy with the outer environment during single-side unloading, which is a damage evolution process with energy dissipation. The true triaxial unloading disturbance rock test system was utilized to perform single-side unloading tests of marble specimens at different unloading rates and axial pressures. The unloading failure characteristics of the marble specimens were revealed from the perspective of energy conversion. Results indicated the following: (1) The marble specimen was more likely to be damaged under the single-side unloading condition than under the loading condition, with the unloading failure strength reaching $80 \%$ of the loading failure strength. (2) Crack propagation under single-side unloading was intermittent. (3) A high single-side unloading rate corresponded to a high release rate of the energy concentrated inside the rock mass, a small amount of energy dissipated due to second failure, insufficient crack propagation, and occurrence of only tensile failure. (4) A large amount of axial strain energy indicated a great amount of energy aggregated inside the rock mass and the generation of tensile stress due to unloading dilatancy. Consequently, a high critical value for splitting the failure of the rock specimen implied large failure-induced energy dissipation and a high failure degree. The study of failure energy evolution mechanism in the single-side unloading of highly stressed rock masses at different unloading rates will provide great guiding significance in controlling underground engineering disasters and guaranteeing construction safety.

\section{Introduction}

Underground engineering excavation is a complicated loading and unloading process. The mechanical properties of rock under unloading conditions are greatly different from those under loading conditions [1-5]. The accuracy of rock mechanical parameters obtained through an unloading test is higher than that of parameters obtained through a loading test in the actual rock excavation process $[6,7]$. The mechanical properties of rock under unloading conditions are influenced by various factors, including stress state at unloading point, unloading stress path, size effect, and rock lithology [8-10]. In addition to the abovementioned influencing factors, unloading rate considerably affects the unloading mechanical properties of rock. A study on rock mechanical properties under different unloading rates will provide theoretical guarantee in improving the stability of surrounding rocks in the underground engineering construction and exerting the optimal effect of supporting structures.

Excavation unloading affects the deformation and failure of surrounding rocks in the unloading phase, and the unloading effect continues on surrounding rocks in roadway after the unloading is completed. However, studies regarding the influence laws of unloading rate on rock mechanical properties are still at an initial stage. Only few scholars have explored this aspect. Huang and Huang [11] investigated the deformation failure and strength characteristics of Jinping 
marble on the basis of tests under different unloading paths and rates. Qiu et al. [12] performed the triaxial unloading test of marble under different unloading rates via the new test path and loading mode and concluded that ultimate bearing capacity was continuously enhanced as the unloading rate increased. Furthermore, Wang et al. [13] conducted axial and confining pressure unloading tests of limestone specimens to investigate their deformation characteristics and the change in their mechanical parameters under different unloading rates of confining pressure. Around the rock mass is not a pure loading state due to the excavation of an underground chamber; specifically, some directions are under the loading state; others are under the unloading state and instantaneously turn from the original three-way hexahedral stress state into the three-way pentahedral stress state [14]. Xu et al. [15] proposed the concept of "single-side unloading" on the basis of this phenomenon, but the existing studies specific to rock mechanical properties under different unloading rates have ignored singleside unloading [16]. Therefore, the true triaxial unloading disturbance test system was used to investigate the mechanical properties of highly stressed rock masses under varying unloading rates. This way could truly reflect the deformation failure laws of surrounding rocks in the highly stressed rock excavation process for the engineering practice.

Previously, stress-strain curves have been mainly used to characterize the rock state under specific stress. Comprehensively reflecting rock failure laws is difficult because the strength criterion established purely by relying on stress-strain curves $[17,18]$. From the angle of thermodynamics, no substance can be damaged without energy, the rock failure process is a state instability phenomenon driven by energy, and rock deformation failure is closely related to its energy conversion. Energy can be accumulated as a scalar quantity [18]. Therefore, energy evolution laws during the deformation failure process can truly reflect the substantive characteristics of rock deformation failure because of its relation to energy. Energy storage, dispersion, and release in the rock deformation failure process are closely associated with the rock failure state and failure mode [19-22]. Related studies have indicated that nonlinear mechanical behaviors in the highly stressed rock excavation, which were driven by energy, had a high correlation with stress environment and mining disturbance; the internal relations of energy dissipation and release with rock strength and overall failure in the rock deformation failure process have also been analyzed [23-25]. Li et al. [21] discussed the energy release and distribution laws of marble damage and rupture under highly stressed unloading conditions and revealed the transformation mechanism of strain energy. Huang and $\mathrm{Li}$ [3] proposed that the loading strain rate greatly affected the dissipation and release of rock strain energy. Furthermore, Huang and $\mathrm{Li}$ [3] systematically analyzed the energy evolution features under the triaxial state of marble and different loading and unloading paths and described the damage process comprehensively on the basis of the conversion rate of strain energy. Meng et al. [5] explored the acoustic emission and energy evolution laws of rocks under uniaxial cyclic loading and unloading actions.

The results above can provide an important reference in investigating the evolution laws of rock deformation failure energy under different loading and unloading rates, but such studies have mostly concentrated on uniaxial and conventional triaxial failure tests while not targeting at energy evolution laws under true uniaxial single-side unloading at different unloading rates. The true triaxial disturbance unloading rock test system was utilized in the present study to perform the single-side unloading test under varying unloading rates. Accordingly, the energy evolution features of the failure process of rock under triaxial compression and single-side unloading conditions at different unloading rates could be examined. The unloading failure features of rock mass were revealed from the angle of energy conversion. The results will provide guiding significance in preventing and controlling underground engineering disasters caused by excavation and unloading.

\section{Principle of Conservation of Energy under True Triaxial Loading and Unloading}

In the true triaxial test process, the tester conducts positive work toward the rock specimen. Given that single-side unloading leads to specimen expansion, negative work is performed on the specimen in a transverse direction.

$$
U_{0}=U_{1}+U_{2}+U_{3} \text {. }
$$

Rock continuously exchanges substances and energy with the outer environment during the deformation failure process, which is a damage evolution process with energy dissipation $[23,26]$, and the rock deformation failure is the product of dynamic energy transfer and conversion. Without the consideration of heat exchange, the total energy absorbed by rock includes elastic strain and dissipated energies, that is,

$$
U_{0}=U_{d}+U_{e}
$$

where $U_{0}$ is the total energy absorbed by rock. $U_{d}$ is the energy dissipated in the rock failure process, and $U_{e}$ is the elastic strain energy absorbed by rock. During the unloading process, the outer environment continuously conducts work toward the rock, where one part is converted into releasable elastic strain energy stored in the rock, and the other part is converted into dissipated energy. This energy facilitates the generation, extension, and penetration of cracks. Ultimately, the rock is continuously damaged. The unloading process of confining pressure leads to the continuous release of the circumferential elastic energy of the rock and the increase in dissipated energy. As a result, the rock failure accelerates. Therefore, studying the energy evolution laws under unloading conditions will be important in accurately identifying rock failure.

By taking the integral of stress-strain curves at any time of the test process, the elastic strain energy absorbed by rock and the energy dissipated in the rock failure process can be obtained as follows: 


$$
\begin{aligned}
& U_{1}=\int_{0}^{\varepsilon_{1}^{t}} \sigma_{1} \mathrm{~d} \varepsilon_{1}, \\
& U_{2}=\int_{0}^{\varepsilon_{2}^{t}} \sigma_{2} \mathrm{~d} \varepsilon_{2}, \\
& U_{3}=\int_{0}^{\varepsilon_{3}^{t}} \sigma_{3} \mathrm{~d} \varepsilon_{3},
\end{aligned}
$$

where $\varepsilon_{1}^{t}, \varepsilon_{2}^{t}$, and $\varepsilon_{3}^{t}$ are the strains of the major, second, and third principal stresses, respectively, at any time of the true triaxial test. The following can be obtained by taking the segmental integral of (3)-(5):

$$
\begin{aligned}
& U_{1}=\sum_{i=1}^{n} \frac{1}{2}\left(\sigma_{1}^{i}+\sigma_{1}^{i+1}\right)\left(\varepsilon_{1}^{i+1}-\varepsilon_{1}^{i}\right), \\
& U_{2}=\sum_{i=1}^{n} \frac{1}{2}\left(\sigma_{2}^{i}+\sigma_{2}^{i+1}\right)\left(\varepsilon_{2}^{i+1}-\varepsilon_{2}^{i}\right), \\
& U_{3}=\sum_{i=1}^{n} \frac{1}{2}\left(\sigma_{3}^{i}+\sigma_{3}^{i+1}\right)\left(\varepsilon_{3}^{i+1}-\varepsilon_{3}^{i}\right),
\end{aligned}
$$

where $n$ is the total number of breakpoints on the stressstrain curve and $i$ represents the breakpoint on the stressstrain curve.

In the true triaxial test process, the expression of the elastic strain energy absorbed by rock at any time is as follows:

$$
\begin{aligned}
U_{e}= & \frac{1}{2}\left\{\frac{\sigma_{1 t}^{2}}{E_{1}^{t}}+\frac{\sigma_{2 t}^{2}}{E_{2}^{t}}+\frac{\sigma_{3 t}^{2}}{E_{3}^{t}}-\mu_{t}\left[\left(\frac{1}{E_{1}^{t}}+\frac{1}{E_{2}^{t}}\right) \sigma_{1 t} \sigma_{2 t}\right.\right. \\
& \left.\left.+\left(\frac{1}{E_{2}^{t}}+\frac{1}{E_{3}^{t}}\right) \sigma_{2 t} \sigma_{3 t}+\left(\frac{1}{E_{1}^{t}}+\frac{1}{E_{3}^{t}}\right) \sigma_{1 t} \sigma_{3 t}\right]\right\},
\end{aligned}
$$

where $E_{1}^{t}, E_{2}^{t}$, and $E_{3}^{t}$ are the elasticity modulus values of the major, second, and third principal stresses, respectively, at any time in the true triaxial single-side unloading process and $\mu_{t}$ is the Poisson ratio at any time.

\section{True Triaxial Single-Side Unloading Test under Different Unloading Rates}

The true triaxial disturbance unloading rock test system (Figure 1) was used in the test to realize independent loading in three mutually perpendicular directions. Then, sudden unloading was applied at one side in a horizontal direction and a side surface of the specimen was exposed to simulate the failure phenomenon due to the release of the energy accumulated on the free face and that in the rock mass after the underground engineering excavation toward the free face. The maximum load of the loading cylinder in the vertical direction $(Z)$ of the system was $5,000 \mathrm{kN}$, and the disturbance cylinder was installed on the lower beam of the vertical loading frame with a maximum dynamic load of $500 \mathrm{kN}$. The maximum loads of two loading cylinders in horizontal directions ( $X$ and $Y$ ) were $3,000 \mathrm{kN}$, where one cylinder was a dynamic one used for rapid unloading. A fulldigital servo measuring and control instrument was used to control loading and unloading, and independent loading and unloading in three directions could be realized. A necessary means for determining the stress state under which the rock experienced the failure could then be provided.

3.1. Testing Program with Different Loading Paths. Table 1 shows the basic physicomechanical marble specimens. Marble specimens of $100 \mathrm{~mm} \times 100 \mathrm{~mm} \times 200 \mathrm{~mm}$ were used. Uniaxial compression test was conducted, and different loading paths under single-side unloading conditions were compared. The loading paths are shown in Figure 2. Figure 2(a) illustrates the conventional uniaxial loading test. As shown in Figure 2(b), single-side unloading was performed when three principal stresses were loaded to the initial stress value (Table 2). Thereafter, loading was implemented using the maximum principal stress until failure. In Figure 2(c), the single-side loading of the minimum principal stress was performed when three principal stresses were loaded to the set value (Table 2) until the unloading was completed.

3.2. Testing Program under Different Unloading Rates. Single-side unloading was performed under different confining pressures and unloading rates. The unloading rates of the specimens were 60,120 , and $300 \mathrm{kN} / \mathrm{min}$. Table 3 shows the instantaneous unloading, initial confining pressures, and different unloading rates. The three directions and six faces of each rock specimen were simultaneously loaded to initial confining pressure at isometric rates (Figure 3(a)). The single-side unloading of minimum principal stress was conducted at the corresponding rate, and the stresses of five other faces remained unchanged (Figure 3(b)). Furthermore, the unloading process continued until specimen failure or the minimum principal stress was zero (Figure 4 ).

\section{Energy Evolution Features of the Single-Side Unloading Test under Different Unloading Rates}

4.1. Stress-Strain Curve Analysis of Different Loading and Unloading Paths. The test analysis of different loading and unloading paths was performed to ensure accurate assessment of the effect of unloading rate on the specimen.

Figure 5 depicts that the uniaxial compression condition was $88 \mathrm{MPa}$. When the first unloading and then loading test path were adopted, the initial loads were 50,20 , and $10 \mathrm{MPa}$, respectively, and the failure strength was $200 \mathrm{MPa}$. Under the first unloading and then loading test path and when $\sigma_{1}$, $\sigma_{2}$, and $\sigma_{3}$ were 140,20 , and $10 \mathrm{MPa}$, respectively, the rock specimen did not go through any failure due to single-side unloading. When the confining pressures used under different unloading rates were 160,20 , and $10 \mathrm{MPa}$ or when the axial pressure was higher than $160 \mathrm{MPa}$, the effect of the unloading rate could be well analyzed. As the axial pressure increased, the single-side unloading was implemented 


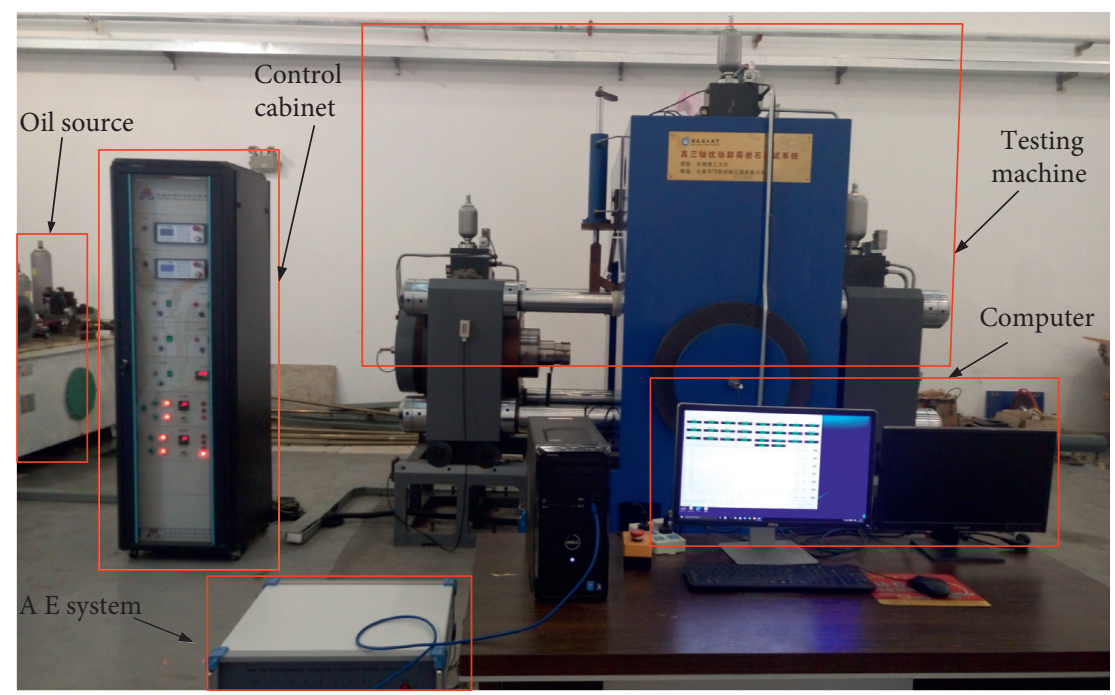

Figure 1: True triaxial disturbance unloading rock test system.

TABLE 1: Mechanical properties of marble material used in this study.

\begin{tabular}{lc}
\hline Property & Value \\
\hline Density, $\rho\left(\mathrm{kg} \cdot \mathrm{m}^{-3}\right)$ & 27 \\
Elastic modulus, $E(\mathrm{GPa})$ & 25 \\
Poisson ration, $v$ & 0.2 \\
Uniaxial compressive strength, $\sigma_{\mathrm{c}}(\mathrm{MPa})$ & 88 \\
Internal cohesion, $c(\mathrm{MPa})$ & 21.4 \\
Internal frictional angle, $\phi\left({ }^{\circ}\right)$ & 38 \\
\hline
\end{tabular}

before $80 \%$ of the peak value, and the rock specimen experienced failure. Therefore, the unloading could more easily cause failure than loading. Therefore, the effect of the unloading rate could be well analyzed only when the confining pressures used under different unloading rates were 160,20 , and $10 \mathrm{MPa}$ or the axial pressure was not greater than $160 \mathrm{MPa}$.

\subsection{Stress-Strain Curve Analysis in the Single-Side Unloading} Test at Different Unloading Rates. The initial confining pressures for the single-side unloading of marble specimens were all 160,20 , and $10 \mathrm{MPa}$, respectively, and the singleside unloading rates were 60,120 , and $300 \mathrm{kN} / \mathrm{min}$ under instantaneous unloading. In the true triaxial test, the pressures of three directions and five faces were kept unchanged. The single-side unloading of the minimum principal stress was a process where deviatoric stress continuously increased. Thus, it belonged to a monotonous effective loading path. The single-side unloading of the minimum principal stress resulted in the extension of the rock specimen toward the free face. Thus, strains were generated. Meanwhile, the strains in the direction of the maximum principal stress were enlarged (Figure 6).

Figure 6 illustrates that, from the starting point of unloading to deformation failure, the first principal stress changed slightly, and even the unloading rebound phenomenon occurred. Therefore, the main causing factor of the unloading deformation failure of the rock specimen was not the first principal stress. After the unloading was started, deformation on the free face was immediately turned into dilatancy. The strain on the unloading face was greater than that of the maximum principal stress. The rebound deformation caused by differential unloading generated tensile stress concentration on the free face of the rock specimen. Thus, the tensile failure increased. In the initial phase of single-side unloading, the free face deformation of the specimen increased slowly and presented a linear relation with free face pressure. Specimen deformation was mainly elastic deformation, followed by irreversible plastic deformation. As the stress on the unloading face continued to reduce, the unloading face deformation suddenly presented a nonlinear growth. Unrecoverable plastic deformation occurred to the specimen, and the microcracks inside the specimen were further generated, extended, and interconnected. Ultimately, penetrating fissure planes formed and failure occurred. However, this nonlinear process was short, that is, the duration when the peak strength of the specimen declined to residual strength was short with evident brittle failure. As the single-side unloading rate increased, the stress value for the specimen to enter the plastic phase was small. When the unloading rate was $60 \mathrm{kN} / \mathrm{min}$, the specimen entered the plastic phase under an unloading value of $4.6 \mathrm{MPa}$. When the unloading rate was $120 \mathrm{kN} / \mathrm{min}$, the specimen entered the plastic phase under an unloading value of 3.8 $\mathrm{MPa}$. When the unloading rate was $300 \mathrm{KN} / \mathrm{min}$, the specimen entered the plastic phase under an unloading value of $1.7 \mathrm{MPa}$. When the unloading rate was instantaneous unloading, the specimen entered the plastic phase under an unloading value of 0.2 MPa. Meanwhile, the strain value of the maximum principal stress declined as the unloading rate increased.

\subsection{Macrofailure Characteristics in the Single-Side Unloading} Test under Different Unloading Rates. According to the previous stress-strain curve rule analysis of the single-side 


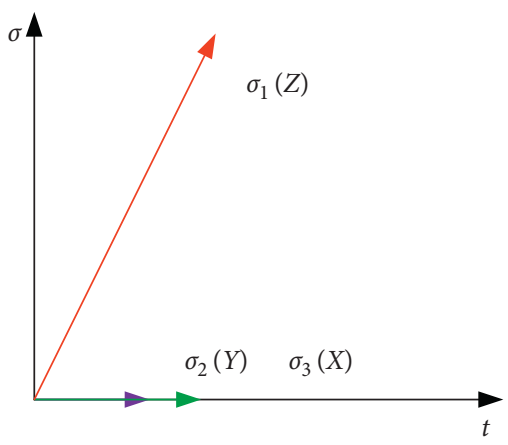

(a)

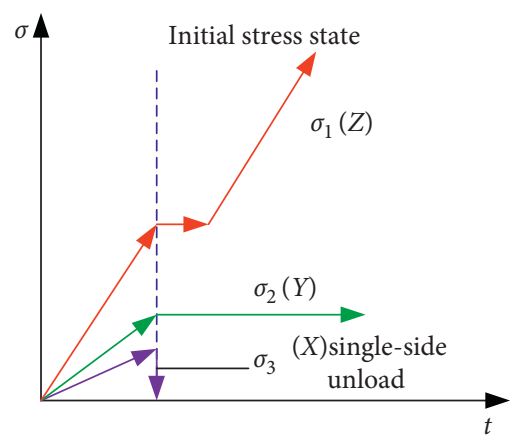

(b)

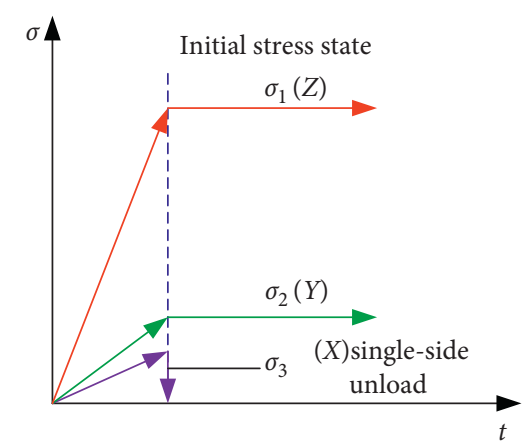

(c)

FIgURE 2: Schematic of different loading and unloading paths. (a) Conventional uniaxial loading. (b) Unloading first and then loading. (c) Loading first and then unloading.

TABLE 2: Initial stress values.

\begin{tabular}{lccc}
\hline Rock number & $\sigma_{1}(\mathrm{MPa})$ & $\sigma_{2}(\mathrm{MPa})$ & $\sigma_{3}(\mathrm{MPa})$ \\
\hline $1^{\#}$ & 0 & 0 & 0 \\
$2^{\#}$ & 50 & 20 & 10 \\
$3^{\#}$ & 140 & 20 & 10 \\
$4^{\#}$ & 160 & 20 & 10 \\
\hline
\end{tabular}

TABLE 3: Different initial confining pressures and different unloading rates.

\begin{tabular}{|c|c|c|c|c|}
\hline Rock number & $\sigma_{1}(\mathrm{MPa})$ & $\sigma_{2}(\mathrm{MPa})$ & $\sigma_{3}(\mathrm{MPa})$ & Unloading rate $(\mathrm{kN} / \mathrm{min})$ \\
\hline $5 \#$ & 160 & 20 & 10 & 60 \\
\hline $6 \#$ & 160 & 20 & 10 & 120 \\
\hline 7\# & 160 & 20 & 10 & 300 \\
\hline $8 \#$ & 160 & 20 & 10 & Instantaneous \\
\hline 9\# & 160 & 20 & 10 & 30 \\
\hline $10 \#$ & 180 & 20 & 10 & 30 \\
\hline $11 \#$ & 200 & 20 & 10 & 30 \\
\hline $12 \#$ & 220 & 20 & 10 & 30 \\
\hline $13 \#$ & 180 & 20 & 10 & 60 \\
\hline $14 \#$ & 180 & 20 & 10 & 120 \\
\hline $15 \#$ & 180 & 20 & 10 & 130 \\
\hline $16 \#$ & 180 & 20 & 10 & Instantaneous \\
\hline
\end{tabular}

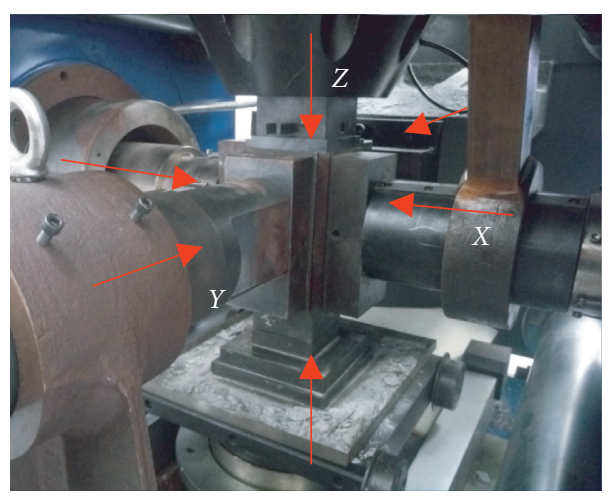

(a)

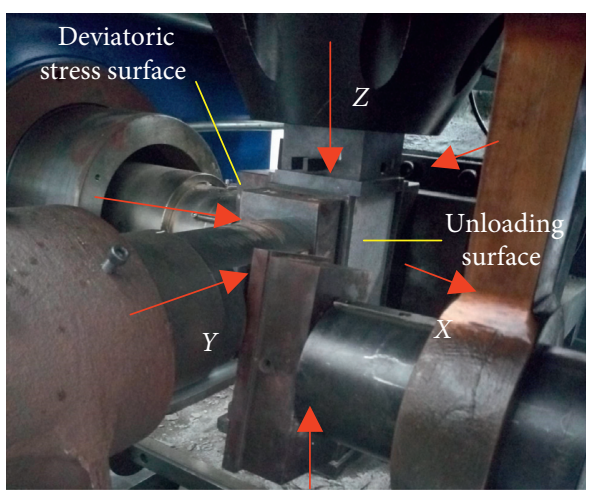

(b)

FIGURE 3: Schematic of specimen loading and unloading. (a) Loading. (b) Single-side unloading. 


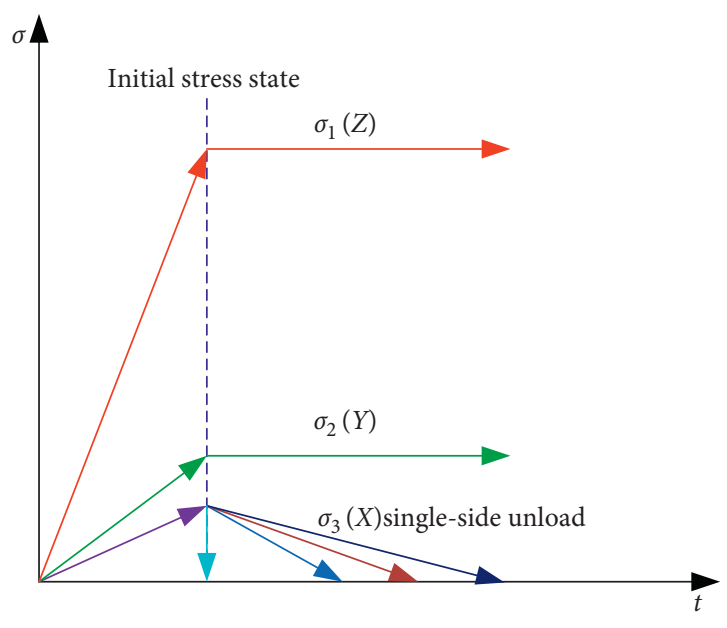

Figure 4: Schematic of loading and unloading paths.

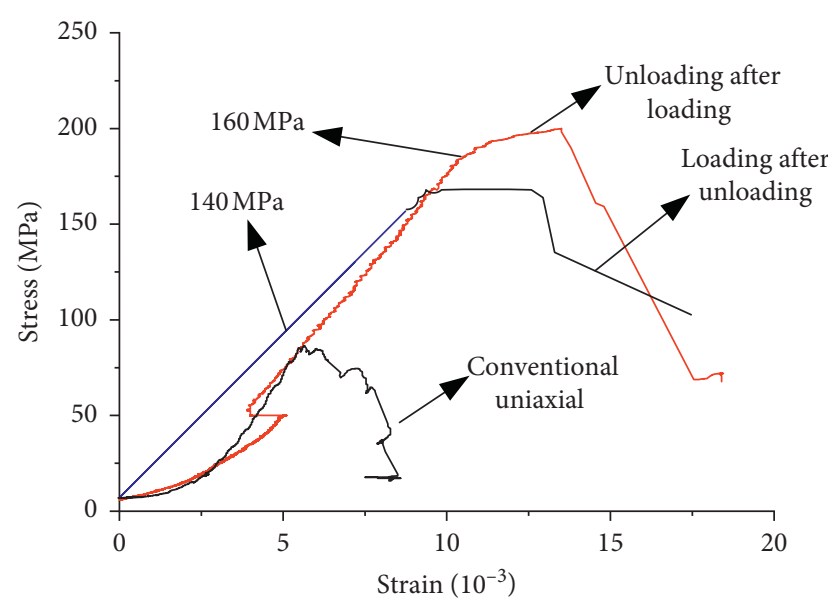

Figure 5: Comparison of stress-strain curves under loading and unloading conditions.

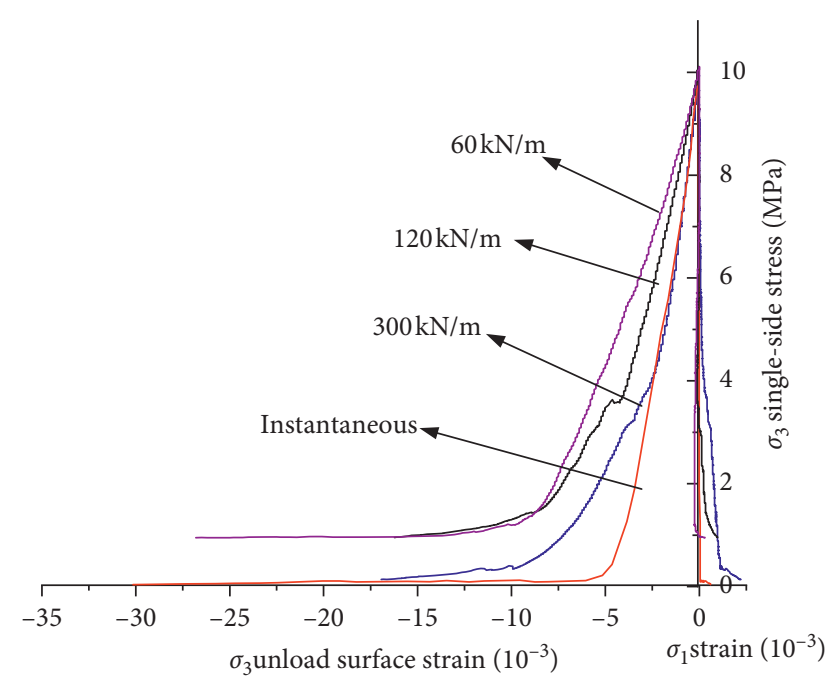

Figure 6: Stress-strain curves of single-side unloading test under different unloading rates.

unloading test of marble specimens under different unloading rates, the macrodeformation failure was further investigated. In the unloading test at different unloading rates, evident splitting board failure was generated on the free face of the rock specimen (Figure 7).

A comparative analysis of failure modes under four different unloading rates in Figure 7 indicated that, as the stress on the unloading face gradually reduced, stresses on the five other faces restricted the extension direction of the specimen, and its strain was mainly extended toward the unloading face. The tensile failure face appeared near the unloading face, which was parallel to the unloading face. Then, the main failure mode near the specimen unloading face was tensile failure. Varying unloading rates caused great differences in the final failure modes of different specimens. When the unloading rate was $60 \mathrm{kN} / \mathrm{min}$, evident splitting board appeared near the unloading face, and several cracks were generated inside it. Under a loading rate of $120 \mathrm{kN} /$ min, a splitting block appeared on the unloading face, but no evident failure emerged inside. Under an unloading rate of $300 \mathrm{kN} / \mathrm{min}$ and instantaneous unloading, the spalling phenomenon appeared only at a local position near the unloading face. As the single-side unloading rate increased, the thickness of the splitting board became small. This result indicated that the rock strength improved as the unloading rate increased. Under a high unloading rate, experiencing plastic deformation was too late for the specimen. The deformation tended to be localized with evident brittleness, and the strength correspondingly improved.

4.4. Energy Evolution Laws in the Single-Side Unloading Test under Different Unloading Rates. As the specimen was encircled by the fixture in the true triaxial test process (Figure 3(a)), the specimen failure process could not be obtained. The energy evolution curve could explain the specimen failure phenomenon due to single-side unloading well. According to the stress-strain curve obtained through the test, the energy calculation method was used to obtain energy values in the single-side unloading process under different confining pressures and the corresponding energy evolution curve.

The deformation failure process of the specimen is a dynamic energy transfer and conversion process. In the true triaxial single-side unloading process, single-side unloading induced releasable elastic strain energy and mediated the increase in energy dissipated inside the medium. Thus, it resulted in the continuous extension of microdefects inside the specimen until failure. During the application process of confining pressure, the specimen was in the compaction phase. The total energy absorbed by the specimen in this phase was stored mainly in the form of elastic strain energy, and the dissipated energy was nearly 0 . Thus, the energy at the starting point of unloading was 0 . Figure 8 illustrates that, when the unloading rate was $60 \mathrm{kN} / \mathrm{min}$, the failure was divided into three phases. Phase I: the released energy gradually increased with the stress reduction on the unloading face, the strain energy of deviatoric stress also gradually increased, and the increase in amplitude of axial strain energy was small. When the axial strain energy of the specimen reached $-0.0124 \mathrm{MJ} \cdot \mathrm{m}^{-3}$, the axial strain sharply increased as time progressed. The specimen also experienced 


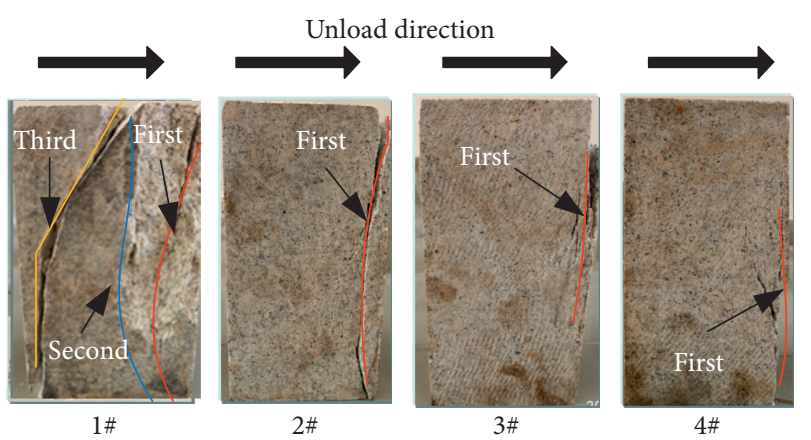

FIGURE 7: Macrofailure graph in the single-side unloading test under different unloading rates.

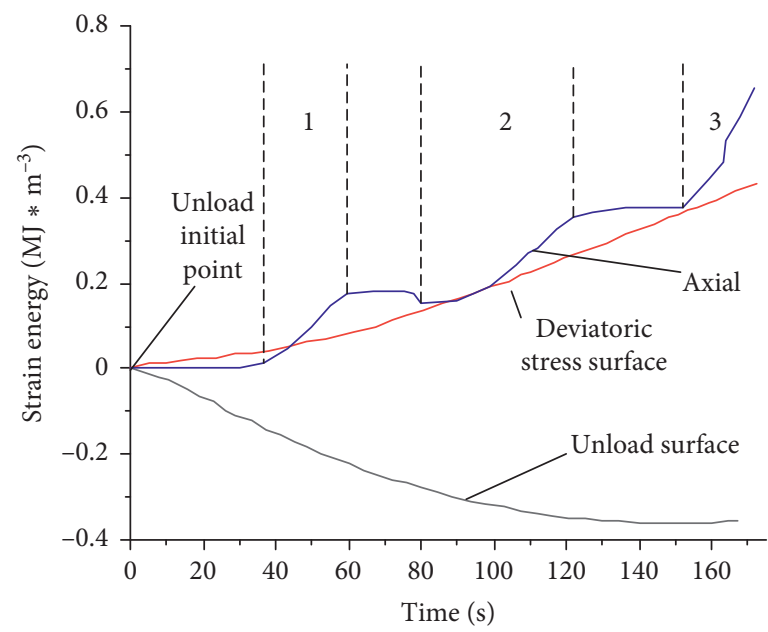

(a)

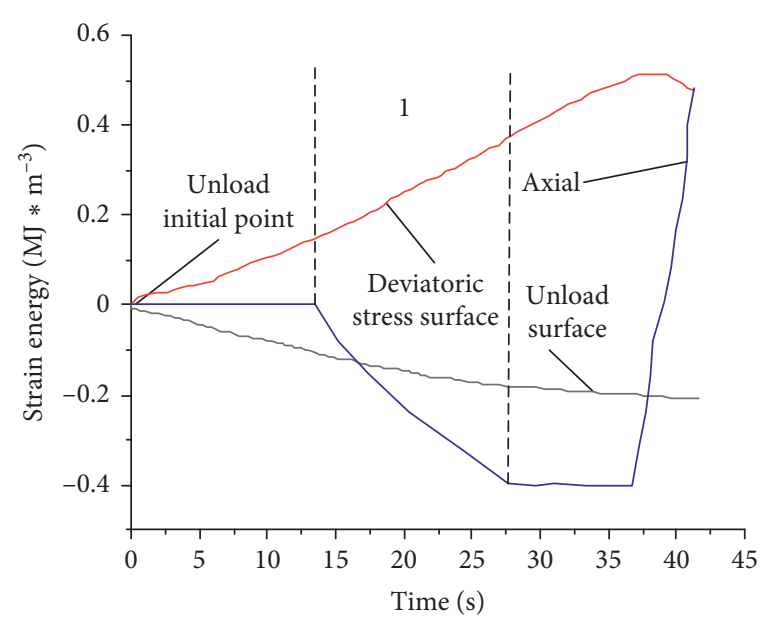

(c)

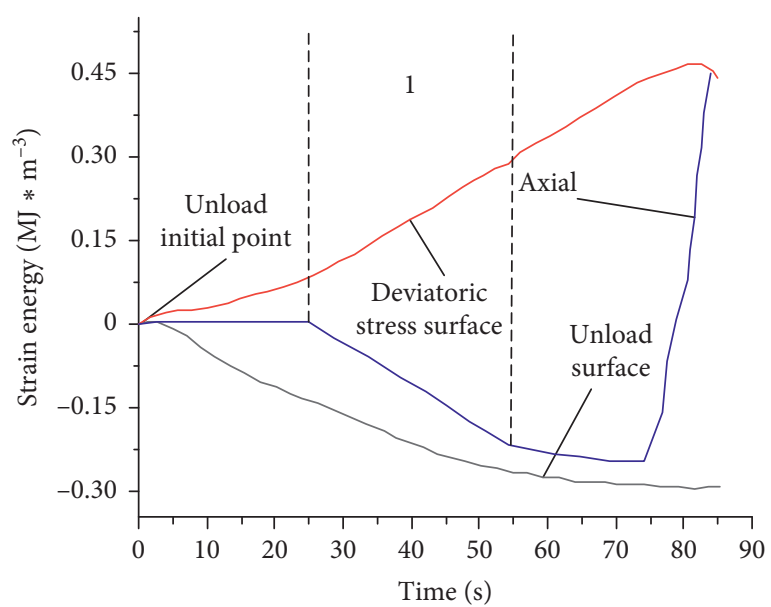

(b)

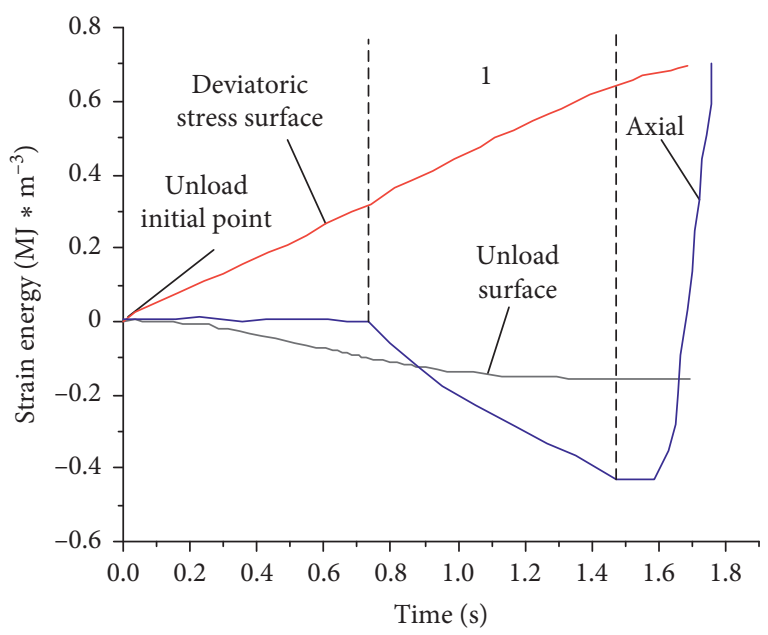

(d)

FIGURE 8: Energy evolution diagram of different unloading rates with an axial pressure of 1,600 kN. Unloading rate of (a) $60 \mathrm{kN} / \mathrm{min}$, (b) $120 \mathrm{kN} / \mathrm{min}$, and (c) $300 \mathrm{kN} / \mathrm{min}$ and (d) instantaneous unloading.

dilatancy. Thus, local splitting failure occurred, which corresponded to the first crack in the $1 \#$ specimen failure in Figure 7. Phase II: the generation of the first crack resulted in energy release, the energy aggregated inside the specimen decreased, the crack propagation stopped, and the energy aggregated in the specimen increased again as the unloading face stress continuously decreased. When the axial strain energy of the specimen reached $0.1762 \mathrm{MJ} \cdot \mathrm{m}^{-3}$, the specimen exhibited failure again. As a result, the second crack was generated, and it corresponded to the second crack of the $1 \#$ specimen failure in Figure 5. Phase III: the energy was released because of the generation of the second crack, the 
energy aggregated inside the specimen decreased, the crack propagation stopped, and the energy aggregated in the specimen increased again as the unloading face stress continuously decreased. When the axial strain energy of the specimen reached $0.3781 \mathrm{MJ} \cdot \mathrm{m}^{-3}$, the specimen experienced failure again. Consequently, the third crack was generated, and it corresponded to the third crack of the $1 \#$ specimen failure in Figure 5. Therefore, the single-side unloadinginduced cracks presented stepwise growth with time. This condition indicated that crack expansion in the single-side unloading process was intermittent, that is, the specimen unloading face experienced the course of tensile stress (propagation of tensile cracks) $\longrightarrow$ stress concentration and release (rapid propagation of splitting cracks) $\longrightarrow$ stress adjustment (splitting cracks stagnated) $\longrightarrow$ failure of stress adjustment (specimen was broken) $\longrightarrow$ stress concentration and release again (second propagation of splitting or shear cracks).

The specimen went through dilatancy as the unloading rate increased. Under an unloading rate of $120 \mathrm{kN} / \mathrm{min}$, the strain energy on the unloading face decreased as its stress declined, and the strain energy on the deviatoric stress face increased. When the axial strain energy reduced to $-0.01032 \mathrm{MJ} \cdot \mathrm{m}^{-3}$, the reduction of axial strain energy accelerated, abrupt dilatancy occurred to the specimen toward the unloading face, and the splitting failure formed, that is, the 2\# crack in Figure 5. As the unloading face stress continued to decline, the axial strain energy increased after keeping constant first. The single-side unloading ended when the axial strain energy increased to $0.7102 \mathrm{MJ} \cdot \mathrm{m}^{-3}$, and the specimen did not experience second failure. As the unloading rate increased, the reduction of amplitude of axial strain energy increased. When the unloading rate was $300 \mathrm{kN} / \mathrm{min}$, the axial strain energy was $-0.3823 \mathrm{MJ} \cdot \mathrm{m}^{-3}$. Under instantaneous unloading condition, axial strain energy was $-0.4125 \mathrm{MJ} \cdot \mathrm{m}^{-3}$. The abovementioned study showed that a high unloading rate corresponded to a short stress adjustment time and a short time needed to reach the stress difference for the local ultimate bearing capacity of the rock. Moreover, the local microcracks presented rapid propagation and interconnection and thus caused instantaneous rock failure. This phenomenon then provided dynamic conditions for the occurrence of dynamic rock failure. The change in rock unloading failure energy mainly occurred from the unloading to failure points. The accurate mastery of the initial time of rock failure will provide a theoretical basis for determining the optimal supporting time and force.

\section{Confining Pressure Effect of Energy Evolution under Single-Side Unloading Conditions}

5.1. Effect of Confining Pressure on Single-Side Unloading Stress-Strain. After specimens 5\#, 6\#, 7\#, and 8\# were loaded to the initial load, the single-side unloading of the minimum principal stress was applied at an unloading rate of $30 \mathrm{kN} /$ min. Figure 9 shows the stress-strain curves. As the unloading face stress decreased, the specimen experienced

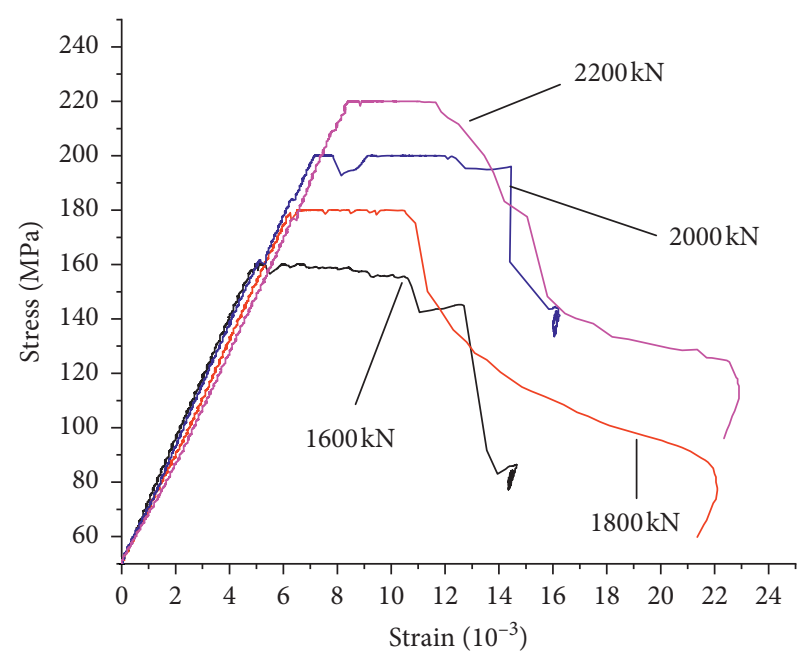

FIGURE 9: Stress-strain curves under different confining pressures.

dilatancy. Given the restricting effect of the second principal stress, the dilatancy extended toward the unloading face, and the axial stress remained unchanged. The specimen exhibited failure when the unloading face stress decreased to a certain value.

\subsection{Effect of Confining Pressure on Single-Side Unloading} Failure Features. Given the existence of confining pressure, the rock specimen was in the elastic phase when loaded to the initial value (axial pressures: 160, 180, 200, and $220 \mathrm{MPa}$ ). Specimens 5\#, 6\#, 7\#, and 8\# experienced splitting failure along the unloading face, and two large diagonal shear cracks appeared at the inner side of each specimen and were accompanied by increasing axial stress. The splitting width gradually increased toward the inside part. The final failure mode is shown in Figure 10. The mode indicated that the second principal stress restricted the lateral expansion of the specimen, which developed toward the free face, during the single-side unloading process of the minimum principal stress. The rock specimen turned from the stress-bearing state into the tensile state due to the sustainable deformation. After the tensile strength was reached, the longitudinal cracks penetrating the rock specimen were generated near the unloading face. These cracks were parallel to the rock slab on the unloading face. The specimen energy was abruptly consumed as the unloading face was continuously unloaded, and the shear failure was triggered when the critical failure value was reached. Therefore, the specimen failure belonged to complex failure and changed from pressure-induced tension (splitting failure) to stress adjustment (shear failure) during the single-side unloading process.

\subsection{Energy Evolution Laws under Different Confining Pres-} sures and Single-Side Unloading Rates. A comprehensive analysis of stress-strain curves and the failure features of specimens $5 \#, 6 \#, 7 \#$, and $8 \#$ showed that, as the initial confining pressure rose, the total energy absorbed by rock continuously increased. The stored elastic strain energy and 


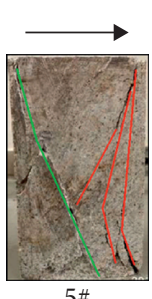

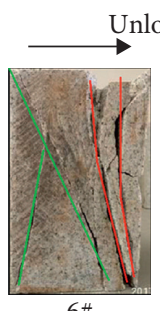

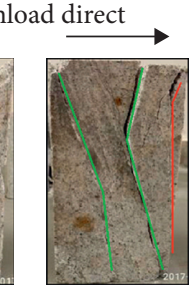

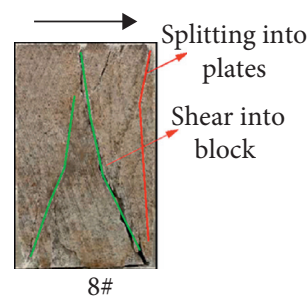

FIGURE 10: Schematic of macrofailure in the single-side unloading under different confining pressures.

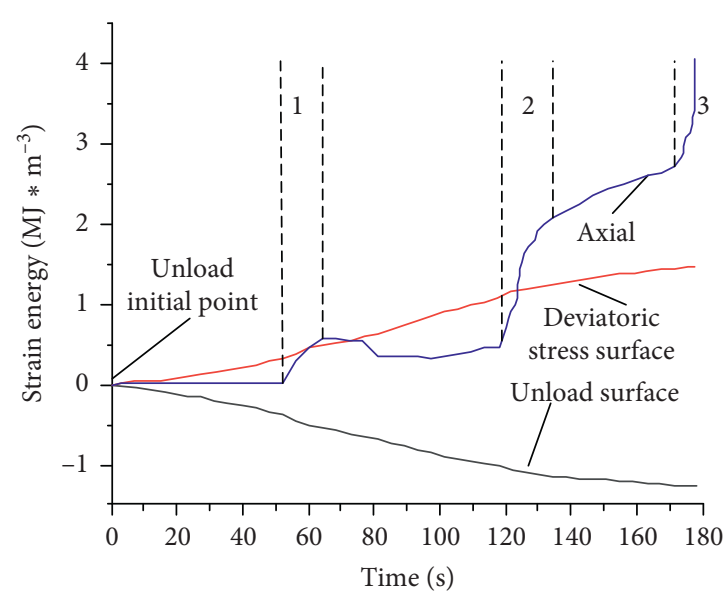

(a)

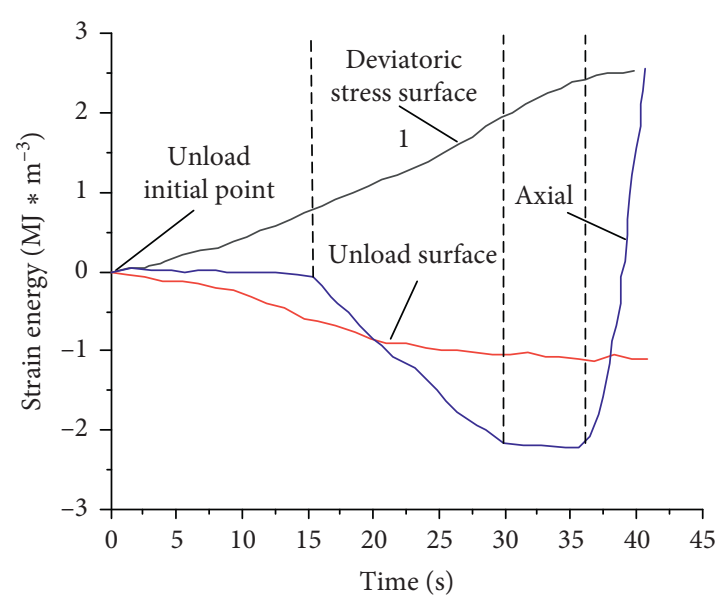

(c)

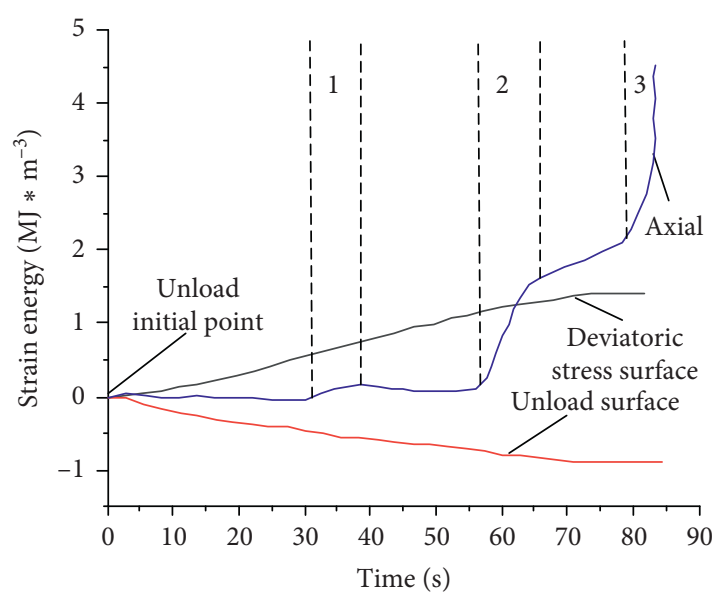

(b)

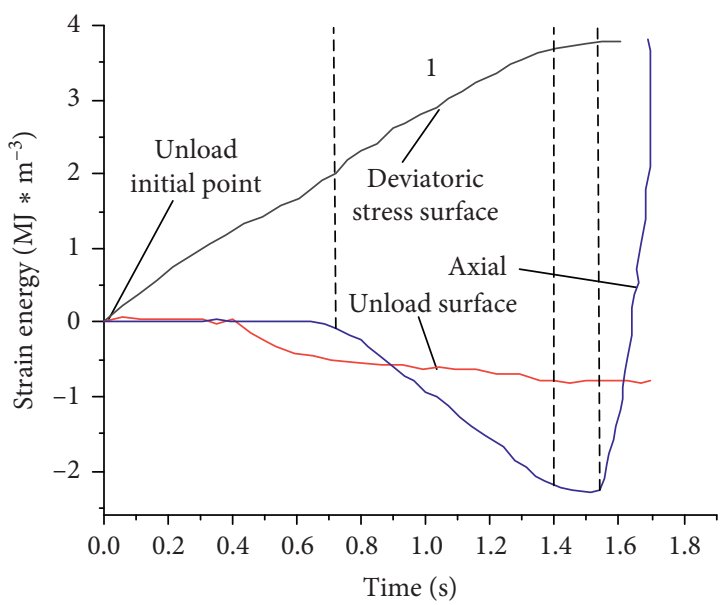

(d)

FIGURE 11: Energy evolution graph under an axial pressure of $1,800 \mathrm{kN}$ and different unloading rates. Unloading rate of (a) $60 \mathrm{kN} / \mathrm{min}$, (b) $120 \mathrm{kN} / \mathrm{min}$, and (c) $300 \mathrm{kN} / \mathrm{min}$ and (d) instantaneous unloading.

the proportion of elastic strain energy in the loading phase in the total energy also increased. The energy needed to cause the same rock failure and bearing capacity and energy dissipated by the rock specimen increased as well. From the peak point to residual strength in the unloading phase, the energy absorbed by the rock was nearly all converted into dissipated energy, where dissipated energy played a dominant role. Therefore, when four different unloading rates, namely, 60,120 , and $300 \mathrm{kN} / \mathrm{min}$ and instantaneous unloading, were utilized, the test results under $1,800 \mathrm{kN}$ of axial pressure were compared with those under $1,600 \mathrm{kN}$ of axial pressure.

A comparison of Figures 9 and 11 showed that two factors, namely, the first unloading rate and the second confining pressure, affected the single unloading failure. Under a low single-side unloading rate, the specimen failure was sufficient and divided into three phases: pressure-caused cracking $\longrightarrow$ splitting failure $\longrightarrow$ shear failure. As the axial pressure increased, the specimen experienced additional unloading phases with further evident multistage failure. 
Under an axial pressure of $1,800 \mathrm{kN}$, shear failure occurred at an unloading rate of $120 \mathrm{kN} / \mathrm{min}$. When the unloading rate was higher than $300 \mathrm{kN} / \mathrm{min}$ and as the unloading face stress decreased, the strain energy on unloading face decreased, whereas the strain energy on the deviatoric stress increased. When the axial strain energy decreased to $-0.3641 \mathrm{MJ} \cdot \mathrm{m}^{-3}$, the reduction of the axial strain energy accelerated, and abrupt specimen dilatancy occurred toward the unloading face. As a result, splitting failure occurred.

\section{Conclusions and Discussion}

(1) The true triaxial disturbance unloading rock test system was used to conduct three-way six-face loading and single-side unloading at different unloading rates, which was approximate to free face generation at the two walls due to on-site roadway (tunnel) excavation. The surrounding rock failure induced by construction progress was accurately simulated. The simulation provided a certain guiding significance to the prevention and control of underground engineering disasters caused by excavation and unloading.

(2) Single-side unloading-induced cracks presented stepwise growth with time. Specifically, the crack propagation was intermittent under the single-side unloading. Large axial strain energy indicated a great critical value of the rock splitting failure caused by the tensile stress, which was generated by dilatancy after unloading and developed from single tensile splitting failure to splitting-shear complex failure. The failure was also violent.

(3) Under the same confining pressure, the single-side unloading rate played a critical role in the rock failure degree. When the single-side unloading rate was low, the internal energy consumed by the rock failure was large, and the failure was sufficient. As the unloading rate increased, the rock mass mainly went through splitting failure due to tensile stress. A high axial pressure indicated a large critical value of the stretching-splitting-shear complex failure rate under single-side unloading and high severity of failure.

\section{Data Availability}

The datasets generated and analyzed during the current study are available from the corresponding author on reasonable request.

\section{Conflicts of Interest}

The authors declare no conflicts of interest.

\section{Authors' Contributions}

All the authors contributed to publishing this paper. Wensong $\mathrm{Xu}$ conceived and designed the experiments, Wensong Xu performed the experiments, Guangming Zhao and Xiangrui Meng revised and reviewed the manuscript,
Siming Kao analyzed the data, Shunjie Huang and Chongyan Liu performed the experiments, and Wensong Xu wrote the paper.

\section{Acknowledgments}

This work was supported by the National Key Research and Development Project of China (2017YFC0603000) and the National Natural Science Foundation of China (51674008).

\section{Supplementary Materials}

Data of the specific time and stress of single-side unloading in the experiment. (Supplementary Materials)

\section{References}

[1] B. Wang, J. B. Zhu, and A. Q. Wu, "Experimental study on mechanical properties of Jinping marble under loading and unloading stress paths," Chinese Journal of Rock Mechanics and Engineering, vol. 27, no. 10, pp. 2138-2145, 2008.

[2] M. N. Bagde and V. Petroš, "Fatigue and dynamic energy behaviour of rock subjected to cyclical loading," International Journal of Rock Mechanics and Mining Sciences, vol. 46, no. 1, pp. 200-209, 2009.

[3] D. Huang and Y. Li, "Conversion of strain energy in triaxial unloading tests on marble," International Journal of Rock Mechanics and Mining Sciences, vol. 66, no. 1, pp. 160-168, 2014.

[4] X. Huang, Q. Liu, Y. Kang, and Y. Pan, “Triaxial unloading creep experimental study of sandy mudstone," Chinese Journal of Rock Mechanics and Engineering, vol. 35, no. S1, pp. 2653-2662, 2016.

[5] Q. Meng, M. Zhang, L. Han, H. Pu, and T. Nie, "Effects of acoustic emission and energy evolution of rock specimens under the uniaxial cyclic loading and unloading compression," Rock Mechanics and Rock Engineering, vol. 49, no. 10, pp. 3873-3886, 2016.

[6] J. S. O. Lau and N. A. Chandler, "Innovative laboratory testing," International Journal of Rock Mechanics and Mining Sciences, vol. 41, no. 8, pp. 1427-1445, 2004.

[7] M. C. He, H. P. Xie, S. P. Peng, and Y. D. Jiang, "Study on rock mechanics in deep mining engineering," Chinese Journal of Rock Mechanics and Engineering, vol. 24, no. 16, pp. 28032813, 2005.

[8] M. Y. Shen, Z. M. Shi, and L. Zhang, "Deformation properties of samples under different loading paths," Chinese Journal of Rock Mechanics and Engineering, vol. 22, no. 8, pp. 1234-1238, 2003.

[9] X. Li, K. Du, and D. Li, "True triaxial strength and failure modes of cubic rock specimens with unloading the minor principal stress," Rock Mechanics and Rock Engineering, vol. 48, no. 6, pp. 2185-2196, 2015.

[10] P. K. Kaiser and B.-H. Kim, "Characterization of strength of intact brittle rock considering confinement-dependent failure processes," Rock Mechanics and Rock Engineering, vol. 48, no. 1, pp. 107-119, 2015.

[11] R. Q. Huang and D. Huang, "Experimental research on affection laws of unloading rates on mechanical properties of jinping marble under high geostress," Chinese Journal of Rock Mechanics and Engineering, vol. 29, no. 1, pp. 21-33, 2010.

[12] S. L. Qiu, X. T. Feng, and C. Q. Zhang, "Experimental research on mechanical properties of deep-buried marble under 
different unloading rates of confining pressures," Chinese Journal of Rock Mechanics and Engineering, vol. 29, no. 9, pp. 1807-1817, 2010.

[13] Z. Q. Wang, L. M. Zhang, and H. Sun, "Experimental study of mechanical properties of limestone under different unloading velocities," Chinese Journal of Geotechnical Engineering, vol. 32, no. 4, pp. 1045-1051, 2011.

[14] B. Haimson and C. Chang, "A new true triaxial cell for testing mechanical properties of rock, and its use to determine rock strength and deformability of Westerly granite," International Journal of Rock Mechanics and Mining Sciences, vol. 37, no. 12, pp. 285-296, 2000.

[15] W. S. Xu, G. M. Zhao, and X. R. Meng, "Modified D-P criterion based on the double-fold reduction method of the true triaxial single-side unloading strength," Chinese Journal of Rock Mechanics and Engineering, vol. 37, no. 8, pp. 1813-1822, 2018.

[16] E. J. Sellers and P. Klerck, "Modelling of the effect of discontinuities on the extent of the fracture zone surrounding deep tunnels," Tunnelling and Underground Space Technology, vol. 15, no. 4, pp. 463-469, 2000.

[17] A. Bogusz and M. Bukowska, "Stress-strain characteristics as a source of information on the destruction of rocks under the influence of load," Journal of Sustainable Mining, vol. 14, no. 1, pp. 46-54, 2015.

[18] E. C. David, N. Brantut, A. Schubnel, and R. W. Zimmerman, "Sliding crack model for nonlinearity and hysteresis in the uniaxial stress-strain curve of rock," International Journal of Rock Mechanics and Mining Sciences, vol. 52, no. 52, pp. 9-17, 2012.

[19] H. Xie, L. Li, R. Peng, and Y. Ju, "Energy analysis and criteria for structural failure of rocks," Journal of Rock Mechanics and Geotechnical Engineering, vol. 1, no. 1, pp. 11-20, 2009.

[20] R. Peng, Y. Ju, J. G. Wang, H. Xie, F. Gao, and L. Mao, "Energy dissipation and release during coal failure under conventional triaxial compression," Rock Mechanics and Rock Engineering, vol. 48, no. 2, pp. 509-526, 2015.

[21] D. Li, Z. Sun, T. Xie, X. Li, and P. G. Ranjith, "Energy evolution characteristics of hard rock during triaxial failure with different loading and unloading paths," Engineering Geology, vol. 228, no. 10, pp. 270-281, 2017.

[22] T. Kanaya and G. Hirth, "Brittle to semibrittle transition in quartz sandstone: energetics," Journal of Geophysical Research: Solid Earth, vol. 123, no. 1, pp. 84-106, 2018.

[23] H. P. Xie, R. Peng, Y. Ju, and H. Zhou, "On energy analysis of rock failure," Chinese Journal of Rock Mechanics and Engineering, vol. 24, no. 15, pp. 2603-2608, 2005.

[24] H. P. Xie, Y. Ju, and L.-Y. Li, "Criteria for strength and structural failure of rocks based on energy dissipation and energy release principes," Chinese Journal of Rock Mechanics and Engineering, vol. 24, no. 17, pp. 3003-3010, 2005.

[25] Z. Zhang and F. Gao, "Research on nonlinear characteristics of rock energy evolution under uniaxial compression," Chinese Journal of Rock Mechanics and Engineering, vol. 31, no. 6, pp. 1198-1207, 2012.

[26] H. P. Xie, Y. Ju, L. Li, and R. Peng, "Energy mechanism of defor-mation and failure of rock masses," Chinese Journal of Rock Mechanics and Engineering, vol. 27, no. 9, pp. 1729-1740, 2008. 